\title{
1. An invitation to fellow epistemic travellers - towards future worlds in waiting: human rights and the environment in the twenty-first century
}

\author{
Anna Grear and Louis J. Kotzé
}

Frames are principles of selection, emphasis and presentation composed of little tacit theories about what exists, what happens, and what matters. ${ }^{1}$

Every book, in an important sense, 'frames' its subject area - not just between two covers but also - inevitably - within a set of epistemic choices or parameters. This book, in particular, is a Research Handbook on Human Rights and the Environment and such a title announces a particular aim. The title 'research handbook' implies a kind of authoritative overview - a certain degree of expert epistemic stability and validity. The term 'frames' the contribution of the book in a particular way: surely, a reader might think a 'research handbook' provides a relatively comprehensive and thoroughgoing initiation into a body of well-accepted, soundly constructed knowledge, covered by experts in its field. It might be comforting to think so - and certainly, many of the contributors to this handbook are world-leaders in the general field of 'human rights', and specifically, in the field of the deeply troubled, increasingly important legal nexus between 'human rights' and the 'environment' - yet matters are not nearly so stable as the term 'handbook' implies.

For a start, even the term 'human rights' (so central to our subject matter) is fraught with ambiguities - as this handbook fully suggests. Critiques of human rights are legion - and compelling - and yet, despite this, human rights-based arguments and claim-making practices seem to play an increasingly important role in the protection not only of human environmental interests but also (though most often indirectly) of the interests of 'the environment' - as various contributions to this handbook reveal.

What is it, a reader might ask, that is so appealing to so many about human rights in particular? Why are human rights so often the very juridical constructs called upon to do such vital work in spite of such important doubts about human rights? Part of the answer, it seems, turns upon the idea that human rights have a particularly potent level of symbolic and rhetorical appeal. They are often understood to be urgent ethical demands, not merely putative legal claims: indeed human rights claims frequently exceed (and simultaneously problematize) the limitations of legislative enactment and enforcement. ${ }^{2}$ Human rights, in other words, have the potential, the tendency and the power to overflow law as powerful signifiers of deeply felt human longing for

T. Gitlin, The Whole World Is Watching: Mass Media in the Making and Unmaking of the New Left (University of California Press 1980) 6.

2 S. Amartya, 'Elements of a theory of human rights' 2004 Philosophy and Public Affairs 32(4): 315-56, 319. 


\section{Research handbook on human rights and the environment}

alternative futures - including, it seems, alternative 'environmental' futures. Their very semantic openness combines with their system-critical energies to produce powerful arguments reaching for a 'not yet' beyond the 'now'.

In addition, when human rights lay claim to a value or to a good, that claim often rises to elevated juridical levels (archetypally, the constitutional level), and the very juridical elevation of human rights, in a circular way, affords particular claims greater legitimacy and protection while simultaneously reinforcing the justificatory basis for future claims of entitlement. ${ }^{3}$ In this sense, it is entirely unsurprising that environmental claims and interests would turn to human rights languages and arguments, given that human rights are understood to be 'high-level public order values or goods at the apex of public policy'. ${ }^{4}$ But such systemic elevation cannot be regarded straightforwardly as a 'human rights victory': legal instruments and human rights institutionalization all too often mute the more system-critical energies of human rights - a fact suggesting the ambivalence of human rights as tools for addressing injustices, whether characterized as human or environmental injustices.

Taken together though, the law-exceeding energies and institutionally elevated juridical status given to human rights make it unsurprising that 'human rights' notwithstanding multiple critiques, co-optations and the limitations of their traditional anthropocentrism - have played, and continue to play, an increasingly important role in mediating the human-environment interface - a context forming an increasingly prominent location for international legal scholarship. Given the growing number and fascinating nature of scholarly engagements with the nexus between 'human rights' and 'the environment' (concepts themselves in need of explicit and sustained interrogation), this handbook seems particularly timely.

We return, in the same spirit of questioning the central categories of reference for this handbook, to our opening doubts concerning the comfortable assumptions that might cluster around the authoritative titular veneer of a 'research handbook'. We wish to use the editorial framing of this handbook as an opportunity to expose to its readers the handbook's own epistemic limitations and the continuing need for epistemic humility.

First, we wish to emphasize the fact that this handbook is a framing containing multiple framings. We wish to acknowledge to readers - right here at the outset - that editorial and authorial epistemic selection has been exercised throughout the entire co-construction of this book. Choices have unavoidably been made: choices of author; choices of subject matter; choices of focus; choices of words and so on and so forth. And every one of these framing choices inevitably involves selections in which a range of conscious and unconscious epistemic factors will have been in play, concerning (as Gitlin puts it above) 'what exists, what happens and what matters'.5

3 L.J. Kotzé, 'Arguing global environmental constitutionalism' 2012 Transnational Environmental Law 1(1): 199-233.

4 B. Weston and D. Bollier, 'Toward a recalibrated human right to a clean and healthy environment: making the conceptual transition' 2013 Journal of Human Rights and the Environment 4(2): 116-42.

5 See $n 1$ above. 
Secondly, we wish to emphasise the fact that books are always provisional, contingent weavings. As Deleuze and Guattari put it, '[a] book has neither object nor subject; it is made of variously formed matters, and very different dates and speeds' ${ }^{6}$ This is all the more true, arguably, of a handbook in which various authors offer their insights to produce a contingent weaving of differing claims to 'knowledge': a plurality, indeed, of knowledges - incomplete ones at that.

These opening observations seem important for us as editors to make, for in this particular handbook epistemic power is itself a central underlying theme. And lying beneath the plethora of questions and themes covered in this handbook we discern perhaps the foundationally urgent question of our era. This is the question of how 'we' (a term rightly problematized by various contributions to this book) should now construct the relationship between 'humanity' and 'the environment' - and between 'human rights' and 'the environment' (themselves each, of course, open to further questions concerning framings).

Appropriately enough, therefore, the book opens with epistemological reflections. First, the reader encounters a reflection critical of the eco-destructive, hegemonic epistemology of mastery lying behind the climate crisis and climate injustices (Adelman), followed by a reflection on the contemporary inescapability of epistemologies of doubt (Philippopoulos-Mihalopoulos) and finishing with a reflection on the foundations of critical engagements with interconnections between human rights and the environment: a reflection that digs beneath the surface to examine operative conceptions of human subjectivity and agency (Code). Indeed, as Code so aptly puts it, the entire endeavour of engaging with adequate reflection upon climate denial (and we would add, the nexus between human rights and 'the environment') demands 'a critical-creative engagement with deeply embedded, yet often uncontested, assumptions about human subjectivity and agency as these (often silently) inform the instituted social imaginary of the affluent west and, albeit tacitly, shape and constrain ecological/ environmental thinking in its wider social-political effects'.

In the light of the depth and power of the assumptions informing the 'instituted social imaginary' of the west - and in particular - its dominance in international legal epistemology - it is essential to engage thoughtfully with core values and closures typical of the field - and in particular - with the parochial political and juridical structures established to mediate and coordinate 'human' relations with 'the world'. Accordingly, in the second section of the handbook, the construction of 'human rights' (Burdon); of legal subjectivity (Grear); of property relations (Coyle); and of state sovereignty (Venter) are examined, partly in an effort to expose certain closures that stifle the space for alternatives - shutting out alternative ways of thinking, muting important critiques, shoring up the status quo, ${ }^{7}$ and partly to offer a range of different ways of 'thinking' these centrally important categories. The global legal order's central closures resist precisely those modes of being and thinking that demand the reversal of law's dominant eco-destructive structures and modes of operation. ${ }^{8}$ Each of the

6 G. Deleuze and F. Guattari, A Thousand Plateaus (Continuum 2004) 4.

7 A. Grear, 'Human Bodies in Material Space: Lived Realities, Eco-crisis and the Search for Transformation' 2013 Journal of Human Rights and the Environment 4(2): 111-15.

8 Ibid. 


\section{Research handbook on human rights and the environment}

categories discussed in this section of the book reflects in distinctive - and also some recognizably common ways - deeply embedded assumptions about human subjectivity, agency and the nature of 'nature'. The contributions in this section of the handbook, taken together - and to differing degrees - challenge precisely the 'instituted social imaginary' of the global legal order, its Eurocentric foundations and its ecological implications.

Law, of course, is a core site of longstanding and powerful epistemic assumptions a key site in which tacit constraints operatively privilege embedded patterns of power and privilege even as they respond to vigorous critical energies emerging in resistive responses to patterns of injustice and environmental degradation. In the third section of the handbook, authors consider the energetic critical aspirations visible (albeit, in some cases, in a muted, institutionally-constrained manner) in constitutional responses to the challenges of human and environmental justice (Kotzé; Boyd), while at the international level, contributors assess the carefully constructed normative structures endeavouring to address the intractability of the many problems facing 'humanity' in the contemporary situation (Morrow; Collins) and so aptly presented by the imagery of the Anthropocene. The Anthropocene, after all, presents a new, planetary life-world characterized by the hitherto inadequately acknowledged complexity of the Earth's systems - a complexity making it all but impossible to establish simple, clear, linear links between causes and effects. The complexities and implications of the Anthropocene demand that future regulatory interventions must be both complexity-sensitive and reflexively critical of law's own epistemic assumptions ${ }^{9}-$ and it is far from clear that the institutionally-constrained pathways of legal response, even expressed in constitutional creativity, has yet revealed the capacity required.

Various regional impulses are also visible. The fourth section of the handbook considers uncomfortable conversations taking place in different regional and national settings, and which directly raise questions of epistemic justice as indigenous peoples and social movement activisms confront the embedded assumptions of the legal status quo (with differing degrees of reception from the current system) (Jessup and Jones; Iorns Magallanes; Thériault). Indeed, law and legal processes - and specifically human rights - appear to be under consistent pressure to become more epistemically receptive - open (albeit to varying degrees) to widening participation (Beyerlin; Hey) and to the development of new modes and of adjudicative sensitivity to the complexity of the issues facing the present and the future (Grant; Scholtz). Without epistemic justice, it can be argued, there is no future justice at all, and if science and law are not opened to alternative, subaltern and diverse ecologies of knowledge(s), it is difficult to imagine 'future' juridical praxes apt for the human and environmental complexities and challenges of the age.

How then, do 'we' (and the question of who 'we' are persists), ${ }^{10}$ confront the question of making the future that 'we' want? The play on the title of the Rio+20 final

9 F. Oldfield et al, 'The Anthropocene Review: Its Significance, Implications and the Rationale for a New Transdisciplinary Journal' 2014 The Anthropocene Review 1(1): 1-7, 3.

10 See, generally, L. Code, Ecological Thinking: the Politics of Epistemic Location (Oxford University Press 2006). 
report in the final section of the handbook is deliberate. ${ }^{11}$ Far from offering a broadly greened market monoculturalism through which to claim 'the future we want', here the future 'we' want is fraught with uncomfortable questions and painful realities. 'The future we want?' reaches not a reassuring - or even a limiting - full stop, but remains troubled by a question mark. The 'future "we" want?' is a space of projected future histories, past, present and future choices and immense epistemic responsibility. The contemporary age is fraught with the outcome of choices emerging from a delusion of epistemic mastery: mass displacements in the face of climate pressures (Lyster); the radically uneven nature of power in the global order (Gonzalez); the relative imperviousness of corporate power to juridical modes of accountability (Simons), and finally - the marketization of 'nature' itself (Khavari). And it remains, as yet, far from clear whether 'hopeful' future-facing initiatives such as the Earth Charter, which seeks to place law in climate- and Earth-facing ethical restraints (Bosselmann) can deliver a future beyond the future history threatened by 'business as usual'.

Ultimately, if this collection, with all its various framings, epistemic choices and contributions, delivers any single insight, it is this: It matters who frames what and how.

Epistemological questions are now fundamentally decisive for the forging of futures beyond the future history so clearly consistent with the fallout of the traditional Eurocentric epistemology of mastery. A new world will be born only if pluralities, inclusion and radically multiple ways of knowing well, knowing ecologically, and knowing responsibly are sought, promoted and celebrated.

We very much hope that this Research Handbook can contribute to the important epistemic journeys undertaken by readers considering the fraught relationships between 'human rights and the environment' in the ecologically stressed world of the twentyfirst century and beyond.

11 See, further K. Morrow, 'Rio+20: A Critique - the Global is Personal: the Personal is Global' 2013 Journal of Human Rights and the Environment 4(1): 1-5. 
Anna Grear and Louis J. Kotzé - 9781782544432 Downloaded from PubFactory at $04 / 26 / 2023$ 02:36:36PM via free access 